\title{
Study of Hearing Impairment in School-Going Children of Ghaziabad
}

\author{
Sushil Gaur ${ }^{1} \quad$ Udita Arora $^{1} \quad$ Vandana Singh ${ }^{1}$ \\ ${ }^{1}$ Department of Otorhinolaryngology and Head and Neck Surgery, \\ Santosh Medical College, Ghaziabad, Uttar Pradesh, India
}

\begin{abstract}
Address for correspondence Sushil Gaur, Department of Otorhinolaryngology and Head and Neck Surgery, Santosh Medical College, Ghaziabad 201002, Uttar Pradesh, India (e-mail: drsushilgaur@gmail.com).
\end{abstract}

\begin{abstract}
Keywords

- hearing impairment

- children

- school-going children

Introduction Hearing is one of the traditional five senses that is also the fastest sense. Inadequate hearing acuity especially during early age has serious effects on the development of a child's personality. According to World Health Organization, around 466 million people worldwide have disabling hearing loss and of these $~ 34$ million are children. Hearing loss in children may occur due to several reasons, but $\sim 60 \%$ of childhood hearing loss occurs from preventable causes. An early detection of these conditions plays an important role in reduction in magnitude of this problem.

Aims and Objectives The motive of this study is to estimate the prevalence of hearing impairment among school-going children in Ghaziabad on the basis of otological findings and tuning fork tests.

Materials and Methods A random sample of 500 school-going children between the ages of 6 to 14 years was selected from children attending ENT OPD in Santosh Hospital, Ghaziabad, over a period of 8 months from July 2019 till February 2020.

Results and Conclusion Prevalence rate encountered in this study was $13 \%$, with unilateral hearing loss being more common than bilateral. The commonest cause was found to be cerumen. A higher prevalence was found in children from semiurban and low socioeconomic background. Since the commonest cause is preventable and readily correctable by proper management, early detection can reduce the burden of this disability.
\end{abstract}

\section{Introduction}

Hearing is one of the five vital senses of humans; it enables us to communicate with others in the way that no other senses can. Hearing impairment is a problem that commonly affects people all over the world. Consequences of hearing loss include inability to appreciate speech sounds and therefore causing a reduced ability to communicate, delay in language acquisitions, economic and educational disadvantages, social isolation, and stigmatization.

The term "Deafness" means little or no hearing at all; the World Health Organization (WHO) recommends that the term "Deaf" should only be applied to those whose hearing impairment is so severe that they will not benefit from any type of hearing amplification. The WHO estimates show that the number of people around the world with disabling hearing loss was around 466 million, of these $\sim 34$ million are children and with $75 \%$ of these residing in developing nations.

It is estimated that in India $\sim 63$ million people suffer from hearing impairment and according to the data by National Program for Prevention and Control of Deafness, four in every 1,000 children are suffering from hearing loss.

Inadequate hearing ability especially during an early age has serious repercussions on the development of a child's
DOI https://doi.org/

$10.1055 / \mathrm{s}-0040-1721898$

ISSN 2581-9607.
(C)2021. Indian Society of Otology.

This is an open access article published by Thieme under the terms of the Creative Commons Attribution-NonDerivative-NonCommercial-License, permitting copying and reproduction so long as the original work is given appropriate credit. Contents may not be used for commercial purposes, or adapted, remixed, transformed or built upon. (https://creativecommons.org/licenses/by-nc-nd/4.0/).

Thieme Medical and Scientific Publishers Pvt. Ltd. A-12, 2nd Floor, Sector 2, Noida-201301 UP, India 
personality leading to poor psycholingual skills resulting in inferior school performance. Factors that affect the quality of speech and language development include date of diagnosis, age of onset of hearing loss, residual hearing, family support, and rehabilitative measures.

Hearing loss of even $15 \mathrm{~dB}$ can cause hearing disability in kids and consequently impairment in mental growth. A child with congenital deafness of severe to profound degree might never develop proper speech. Conductive hearing losses are amenable to timely intervention by conservative or surgical measures.

Most of the times mild and unilateral hearing losses remain undetected due to unawareness or reluctance of the child to express the problem in front of their folks and teachers. An early detection of these conditions plays an important role, as remedial steps can be initiated at the earliest before chronic pattern of disease sets in.

\section{Aim and Objectives}

Following are the aims of this study:

- To adjudge the prevalence of hearing impairment in school-going children of Ghaziabad.

- To find the cause of hearing loss based on otological findings and tuning fork tests.

\section{Materials and Methods}

A random sample of 500 school-going children between the ages of 6 to 14 years was taken for the study from ENT OPD of Santosh Hospital, Ghaziabad, over the period of 8 months from July 2019 till February 2020. The study protocol was cleared by institutional ethical committee. All the children included in this study were with the permission of their parents/guardians. Children with previous history of audiological intervention and children with chronic diseases who were on medication were excluded from the study.

A proper history was taken giving importance to any aural, nasal, and throat complaints; past history of any trauma, speech development, exposure to pathogens, and birth history was taken, and personal history in regard to their socioeconomic status was taken from the parents and recorded.

Children were subjected to a detailed ENT examination, otoscopic examination, and tuning fork tests.

All children who were detected with clinical abnormality were counselled for further detailed examination and investigations.

\section{Observations and Results}

Five-hundred school-going children aged between 6 and 14 years who attended ENT OPD at Santosh Hospital, Ghaziabad, were examined to assess hearing impairment.

Sixty-five children out of 500 were found having hearing loss indicating a prevalence rate of $13 \%$ among the school-going population (-Fig. 1).
A slightly higher percentage of male children (52.30\%) was found to be affected than female children (47.69\%) (-Table 1; - Fig. 2).

It was observed that children belonging to lower socioeconomic class (64.61\%) were significantly more affected than middle class (26.15) and higher socioeconomic class (9.23\%)

\section{(-Table 2; - Fig. 3).}

Through tuning fork tests, it was found that conductive type (87.69\%) of hearing loss was much more prevalent that sensorineural type (12.30\%) (-Table 3; - Fig. 4).

Among the affected children, bilateral hearing loss $(46.15 \%)$ was more common than unilateral hearing loss (53.84\%) (-Table 4; - Fig. 5 ).

Most common presenting complain was ear pain (32.30\%) followed by ear discharge (24.53\%) and ear itching (21.53\%) (-Table 5; - Fig. 6).

Most common finding in our study on the basis of otoscopic examination was found to be cerumen (36.92\%) followed by otomycosis (30.76\%) and tympanic membrane perforation $(16.92 \%)$ (-Table 6; - Fig. 7).

\section{Discussion}

In the following study, a total of 500 school children were screened, out of these 65 were found to have hearing impairment due to various causes. Overall prevalence was $13 \%$; these results are very similar to those of Olusanya et al, ${ }^{1}$ Tuli et $a l,{ }^{2}$ and Mishra et $a,^{3}{ }^{3}$ in which prevalence rate of $13.9,12.25$, and $11.7 \%$ was found, respectively. A slight difference in gender distribution was noted with male children being more affected (52.30\%) than females (47.69\%). The maximum number of cases of belonged to low socioeconomic strata.

The results (64.61\%) are similar to those by Gupta et al ${ }^{4}$ but inverse results have been stated by Mishra et al. ${ }^{5}$

Bilateral type of hearing loss was more common (53.84\%) in our study than unilateral type of hearing loss (46.15\%) similar to those of Hamida et al. ${ }^{6}$

Overall conductive hearing loss (87.69\%) was significantly more than sensorineural hearing loss (12.30\%). This closely agrees with the studies of Tuli et $\mathrm{al}^{2}(99.59 \%)$, Elahi et al ${ }^{7}$, Rao et al $(81.6 \%),{ }^{8}$ Maharajan et al ${ }^{9}(87 \%)$, Sapra et $\mathrm{al}^{10}(96.79 \%)$ who also noted a higher incidence of conductive hearing loss among children.

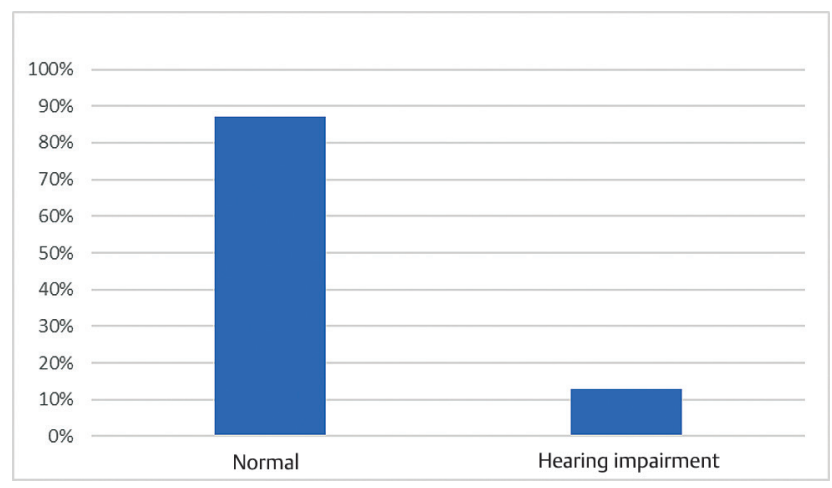

Fig. 1 Prevalence of hearing loss in school-going children. 
Table 1 Gender distribution

\begin{tabular}{|l|l|l|}
\hline Gender & Total & Prevalence (\%) \\
\hline Male & 34 & 52.30 \\
\hline Female & 31 & 47.69 \\
\hline
\end{tabular}

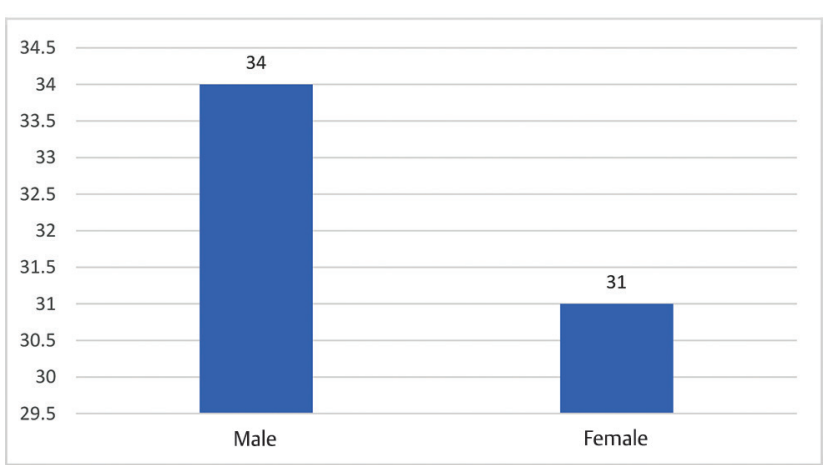

Fig. 2 Gender distribution.

Table 2 Socioeconomic distribution

\begin{tabular}{|l|l|l|}
\hline Socioeconomic status & No. of children & Prevalence (\%) \\
\hline Upper class & 6 & 9.23 \\
\hline Middle class & 17 & 26.15 \\
\hline Lower class & 42 & 64.61 \\
\hline
\end{tabular}

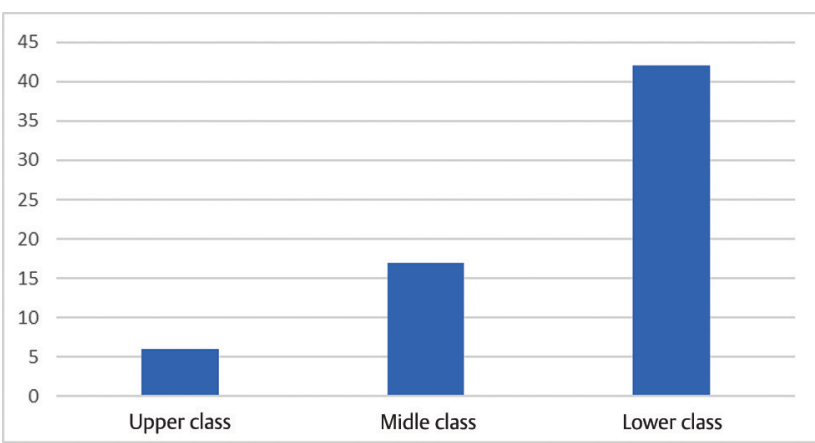

Fig. 3 Socioeconomic distribution.

Table 3 Type of hearing loss

\begin{tabular}{|l|l|l|}
\hline Type of hearing loss & No. of children & $\begin{array}{l}\text { Prevalence } \\
\text { (\%) }\end{array}$ \\
\hline Conductive hearing loss & 57 & 87.69 \\
\hline Sensorineural hearing loss & 8 & 12.3 \\
\hline
\end{tabular}

In this study of 65 patients of hearing impairment, most common accompanying complaint was of ear pain (32.30\%) followed by ear discharge (24.61\%).

Most common cause as per otoscopic finding within this study was found to be wax (36.92\%); this figure closely resembles the results of Mishra et $\mathrm{al}^{11}$ who observed that out of all cases of hearing impairment, $45.2 \%$ of children were having wax, also similar to Thakur et al ${ }^{12}(45.76 \%)$ and Olusanya ${ }^{13}$ who documented $52.6 \%$ of school-going children having impacted wax in Lagos. Studies of Sapra et $\mathrm{al}^{10}$, Rao et $\mathrm{al}^{8}$, and Nogueira and Mendonça ${ }^{14}$ also have similar results.

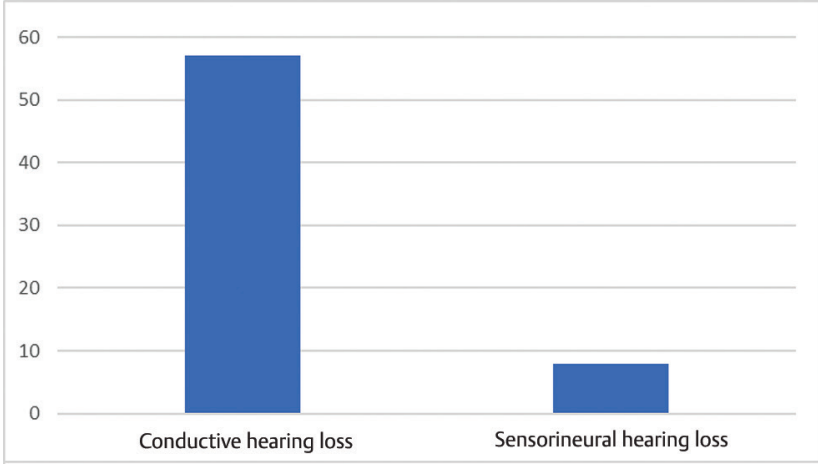

Fig. 4 Type of hearing loss.

Table 4 Laterality of hearing loss

\begin{tabular}{|l|l|l|}
\hline Type of hearing loss & No. of children & Prevalence (\%) \\
\hline Unilateral & 30 & 46.15 \\
\hline Bilateral & 35 & 53.84 \\
\hline
\end{tabular}

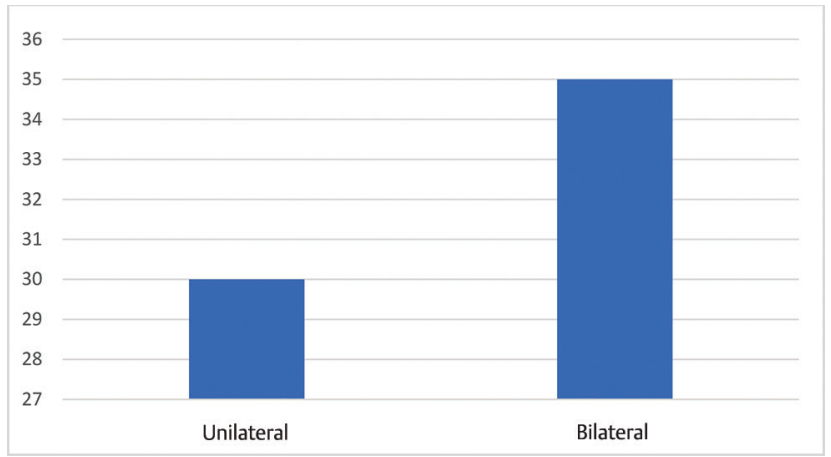

Fig. 5 Laterality of hearing loss.

Table 5 Symptomatic distribution

\begin{tabular}{|l|l|l|}
\hline $\begin{array}{l}\text { Symptoms/Predisposing } \\
\text { factors }\end{array}$ & $\begin{array}{l}\text { No. of } \\
\text { children }\end{array}$ & Prevalence (\%) \\
\hline Ear pain & 21 & 32.30 \\
\hline Ear discharge & 16 & 24.61 \\
\hline Ear itching & 14 & 21.53 \\
\hline Trauma & 6 & 9.23 \\
\hline Inferior turbinate hypertrophy & 5 & 7.69 \\
\hline Deviated nasal septum & 3 & 4.61 \\
\hline
\end{tabular}

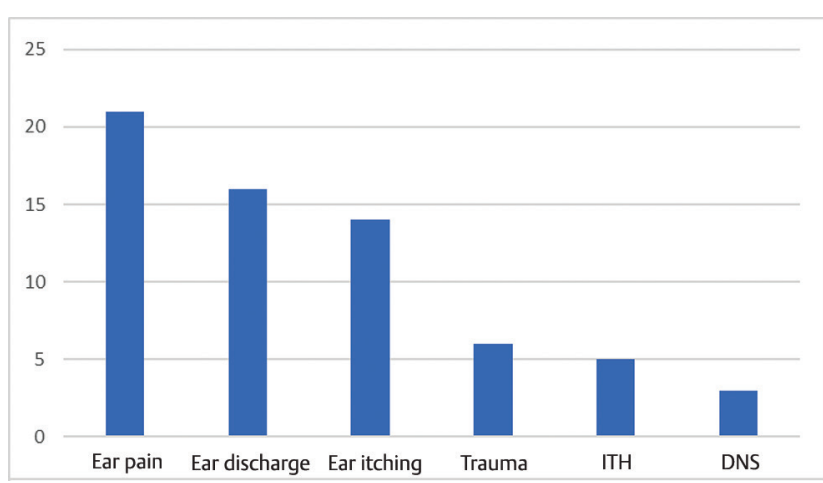

Fig. 6 Symptomatic distribution. 
Table 6 Examination findings

\begin{tabular}{|l|l|l|}
\hline Otoscopic findings & No. of children & Prevalence (\%) \\
\hline Wax & 24 & 36.92 \\
\hline Otomycosis & 20 & 30.76 \\
\hline $\begin{array}{l}\text { Tympanic membrane } \\
\text { perforation }\end{array}$ & 11 & 16.92 \\
\hline Ear discharge & 7 & 10.76 \\
\hline Otitis externa & 3 & 4.61 \\
\hline
\end{tabular}

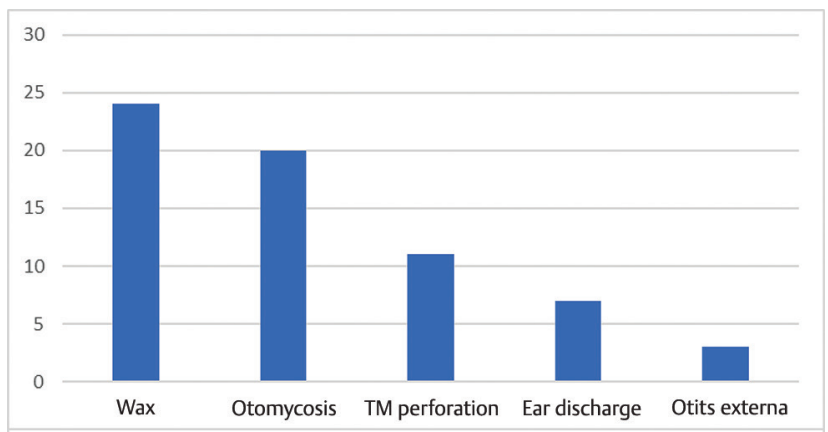

Fig. 7 Examination findings.

Otomycosis was found to be the second most common (30.76\%) cause for hearing loss in this study in comparison to the Sapra et al study ${ }^{10}$ (7.63\%).

Other nose and throat findings were rhinitis (inferior turbinate hypertrophy) in $7.69 \%$ of children and deviated nasal septum in $4.61 \%$. About $9.23 \%$ also gave history of trauma followed by hearing loss.

\section{Conclusion}

Hearing loss in children can mostly remain undetected due to unawareness or sometimes reluctance of children to express this disability in front of their parents and teachers. In our study, a prevalence of $13 \%$ was found in otherwise apparently healthy children.

Most of the causes of hearing impairment in school-going children are conductive in nature and an early recognition leads to reversal of the problem by a simple medical or surgical intervention. Majority of the causes like wax or mycosis that leads to hearing impairment are temporary in nature and once removed, hearing returns to normal without any permanent disability. Subsequently causes like otitis media if not early detected may lead to permanent damage if early corrective measures are not taken.

If hearing loss is noted at birth, it is most likely to be sensorineural in nature. This may accompany many other syndromes like Usher syndrome, Pendred syndrome, Waardenburg syndrome, Otosclerosis, Treacher Collins syndrome, and Alport syndrome. However, sensorineural hearing loss of acquired nature can be due to maternal use of ototoxic drugs, maternal rubella, birth trauma, and hyperbilirubinemia.

Inferences drawn from this study signify that early screening is of uttermost importance in spotting hearing loss in children; steps should be taken to extend screening programs in all the schools.
Otoscopic examination has been confirmed to be the most effective equipment time and again in preliminary screening of ear-related problems. It is less time consuming and all the more informative tool. Otoscopic examination combined with tuning fork tests was effective in detecting type of hearing loss, which is important for further evaluation of the type of lesion responsible for hearing impairment.

Lastly, it is important to advise parents of such children about remedial available for the reversal of their child's hearing impairment, also about the preventive measures that can be inculcated in daily routines.

Parents should be counseled to support and encourage their children dealing with permanent hearing disability thus helping them develop adequate speech and language skills.

\section{Conflict of Interest}

None declared.

\section{References}

1 Olusanya BO, Okolo AA, Ijaduola GTA. The hearing profile of Nigerian school children. Int $\mathrm{J}$ Pediatr Otorhinolaryngol 2000;55(3):173-179

2 Tuli BS, Parmar TL, Kumar S. Incidence of deafness in school going children. Indian J Otolaryngol 1988;40(4):137

3 Mishra SC, Sharma H, Bhusan V, Dayal D. Preliminary study of hearing handicap in school going children. Indian J Otolaryngol Head Neck Surg 1992;1:3

4 Gupta D, Gulati A, Gupta U. Impact of socio-economic status on ear health and behaviour in children: a cross-sectional study in the capital of India. Int J Pediatr Otorhinolaryngol 2015;79(11):1842-1850

5 Mishra SC, Shah PK, Kandapal N. Hearing retardation amongst school age Bhutanese refugees. Indian Journal of Otology 2002; $8(1): 5-8$

6 Hamida O, Shoukrya T, Shehatab W. Prevalence and pattern of hearing loss in children in house-held national survey in Egypt. Ejentas 2010;11:12

7 Elahi MM, Elahi F, Elahi A, Elahi SB. Paediatric hearing loss in rural Pakistan. J Otolaryngol 1998;27(6):348-353

8 Rao RS, Subramanyam MA, Nair NS, Rajashekhar B. Hearing impairment and ear diseases among children of school entry age in rural South India. Int J Pediatr Otorhinolaryngol 2002;64(2):105-110

9 Maharjan M, Bhandari S, Singh I, Mishra SC. Prevalence of otitis media in school going children in Eastern Nepal. Kathmandu Univ Med J (KUMJ) 2006;4(4):479-482

10 Sapra G, Srivastava SP, Modwal A, Saboo R, Saxena G, Gyanu J. Hearing assessment of school going children of various schools in Jaipur, Rajasthan. Scholars Journal of Applied Medical Sciences 2015;3(2B):638-645

11 Mishra SC, Shukla GK, Bhatia N, Mishra A, Kandpal N. Ear health care and promotion of hearing amongst school children of slum areas. Indian J Otolaryngol 1992;10:18-23

12 Thakur SK, Acharya R, Singh SK, Ghimire N. Ear diseases in school going children of Sunsari and Morang districts of Nepal. Journal of Chitwan Medical College 2017;7(1):16-19

13 Olusanya BO. Hearing impairment in children with impacted cerumen. Ann Trop Paediatr 2003;23(2):121-128

14 Nogueira JC, Mendonça MdaC. Assessment of hearing in a municipal public school student population. Rev Bras Otorrinolaringol (Engl Ed) 2011;77(6):716-720 